\title{
Deepen Construction Project Management, Promote "Project Productivity" Theory
}

Wu Tao

Vice-chairman and Secretary-general of

China Construction Industry Association

In the report to 18th national Congress, The Communist PARTY OF CHINA(CPC) MADE INCISIVE EXPLANATION AND SCIENTIFIC ILLUSTRATION FOR THE SOCIAL AND ECONOMIC DEVELOPMENT OF CHINA FROM THE HEIGHT OF PRACTICAL THEORIES, AND PUT FORWARD THE OVERALL LAYOUT OF BUILDING SOCIALISM WITH CHINESE CHARACTERISTICS IS FIVE IN ONE, WITH THE OVERALL TASK AND MAIN OBJECT OF ESTABLISHING THE MODERATELY PROSPEROUS SOCIETY IN AN ALL-ROUND WAY ON THE 1OOTH ANNIVERSARY OF THE ESTABLISHMENT OF THE CPC, BUILDING THE STRONG, DEMOCRATIC, CIVILIZED AND HARMONIOUS MODERNIZED SOCIALISM COUNTRY on the 100th anNiversary of the People's Republic of China AND REALIZING THE GREAT REJUVENATION OF THE CHINESE NATION. It has emphasized that eight do's should be carried out to grab the new victory of socialism with Chinese characteristics in new historical conditions, among which insisting of liberating and developing social productive forces is specially emphasized, and it further ensured to take the transformation of economic development mode as a strategy choose for realizing each target in the new era. So how can the construction industry of our nation alter its way of development, and achieve sustainable development? In recent years, we have been researching and exploring how to deepen and innovate construction project management. In 2010, the Construction Project Management Committee (CPMC) of China Construction Industry Association (CCIA) has organized a research group, they did a further investigation on speeding up the transformation of construction development mode and deepening the engineering project management, have convened conversaziones and seminars for several times, and finally proposed this basic train of thought based on synthesizing demonstrations from specialists and scholars and all enterprises, i.e. Innovatively improve "one theory", definitely transfer "two competitions", pointedly insist on "three improvements", precisely hold "four trends", and accelerate the realization of "five transformations". 
Innovatively Promote

"Project Productivity" Theory

According to the speaking spirit of comrade Deng Xiaoping, the chief designer of China reform that the construction industry should become the pillar industry of the national economy in the 8 os of last century, our country has firstly taken the construction industry as the pilot industry in reform of the city economy system. In 1987, five ministries specified the implementation of "Project Method" construction in the construction industry as a breakthrough for carrying out the management system reform of the construction enterprise and comprehensively promoted the project management in engineering construction. We usually call this reform in this period as the first reform of production mode. It is in the process of change that the construction industry, from the implementation of "project method" to executing two separate tier within the enterprise, established new operation mechanism of project management, realized the progress and development of project management, and innovatively put forward the theory of "project productivity", and the process embodied the organic complementation between the three and constituted the rigorous logic relation.

(1) The main basis and origin for proposing the theory of "Project Productivity"

On the whole, the theory of "Project Productivity" is proposed and formulated under the guidance of MarxismLeninism, Mao Zedong Thought and the theory on the building of socialism with Chinese characteristics, based on the reform and development practice of Chinese construction industry, promoting the engineering management experiences of Lubuge to Chinese construction enterprises so as to conduct the conclusion and sublimation of practical experience of production mode reformation. There are mainly three aspects:
First, the improvement of the theoretical recognition has been achieved with the spreading of the practice experience of the Lubuge engineering project management. As we all know, Lubuge hydroelectric power station project on Huangnihe, a tributary of Nanpan River in Luoping county, Yunnan province is the first capital construction project using loans of the World Bank in the early era of China's reform and opening-up period. China Issued international invitation for bids based on the regulations of the World Bank and Japan Taisei won the bid with a price 44 percent lower than the base tender estimate, completed the construction 4 months ahead of the plan with excellent engineering quality and the contract settlement was controlled within a reasonable range. The advanced management mechanism, dynamic project team, scientific construction method, ordered working site and effective, low-consumed and superior management theory showed in Lubuge engineering project management brought great impact on Chinese building field and construction management system. Through comparing, concluding and reflecting, we see the disparity and find the crux of the problem. We deeply realized that the major reasons of engineering construction situations of "bottomless investment and marathon construction-period" caused by planned economic system lie in the limitation of construction production mode, the specific performance lies in "three backwardness", namely, backward possession method of essential productive factors, backward control method of essential productive factors and backward type of flow of essential productive factors. Both the production organization form in which the enterprise is treated as a unit and the old production relations hinder the development of the productive forces of the construction industry seriously, which makes the enterprise difficult to adapt to the challenges of market competition. The successful experience of Lubuge project management is that it implemented the method in which the engineering project itself is treated as the object, used the internal laws of the project to organize the production, which is the project construction method proposed by project department. Its meaning has two basic points: Firstly, it carries out the internal management system reform of the construction enterprises, breaking the three-level management and administrative mechanisms of economic accounting to enable the enterprises to accommodate to the needs of the new way of project management. Secondly, it establishes the project management department, treating the project as the object, and organizes the production in accordance with the internal laws of the project management.

\section{Second is about enlightenment of} Marx's theory of productive forces. According to Marxism, social relationships among people formed in the process of material production constitute the production relations, which is the driving force to achieve the liberation and development of productive forces. Among them, the laborer is the most active element; means of production are the symbol of productivity. The productivity level is mainly determined by the elements that constitute the productive forces, namely the combination and adaptation degree between the laborer and the productive material as well as the object of labor, and the compacter they combined, the higher the construction productivity level is. However, the essential productive factors should be combined and distributed through a certain method of production organization, in order to form a real productivity. Marx divided 
productivity into three levels, that is "social productivity, sectional productivity, and enterprise productivity", for universal phenomenon. For the reality of construction activity, engineering project is an efficient carrier of production factors' transformation into practical productive forces, and the final foothold to emancipate and develop construction productive forces. Therefore, there exists a fourth level in construction productive forces, that is, project level, which is exactly the project productive forces we put forward. The level of project management is crucial to the liberation and development of productive forces of building industry. The research and development of building productivity could not leave the project management level. This is the enlightenment for we cognizing the essential feature of productive force of construction industry from the Marxist productive force theory.

Third, it is determined by the basic features of the construction industries' essential productive factors and productivity. This is because the form of the material production in building industry is different from other industrial sectors, and the combination of factors of production in building industry has its particularities: The first one is the coexistence of on-site direct combination and away-from-site indirect combination of the laborer and the productive material in the spatial performance; the second is, laborer and means of production assume that the productivity is realized by intermittent combination at a time; the third is that the combination of labor and productive material shows a variety of forms of mechanization, semi-mechanization, manual labor and so on. Therefore, for construction industry, only the laborer is closely combined with the means of production through the engineering project, can factors of production be transformed into real productivity.

\section{(2) The frame structure of "Project} Productivity" theory system

As the outcome deriving from the combination of Marxism classical theory and practice of the reform and development of Chinese construction practice, "project productivity" forms a basic framework system after going through the process of practice, cognition, repractice and recognition.

1. The Concept of "Project Productivity"

"Project productivity" was proposed in accordance with the hierarchy theory of Marxist productive forces theory and the particularity combining production factors and sites in construction enterprise. Borrowing Marx's definition that "Productivity is the ability of human beings to conquer and reform the nature", we describe the notion of project productivity as that "Project productivity is the ability of the department of project manager to achieve the goal of project construction". Only by making the optimal configuration and achieving the dynamic combination for 3 elements of laborer, subject of labor and means of labor in the level of engineering project can the practical productivity be formed better. 2. Connotation of project productivity

Project productivity reveals the relation between the productivity of construction enterprise and that of project, namely, enterprise productivity is the premise and condition of project productivity, and the project productivity is the foothold of productivity of construction enterprise. Project productivity possesses technical attributes, property of value and cultural attribute. The connotation of project productivity takes production organization and management style as the core, takes technical progress and management innovation as the support, takes optimal configuration of project resources as basic, centers on the target of engineering and project construction, and reflects socialized mass production caring for people. Seeing from the extension, project productivity is the unity of material productivity, cultural productivity and talents growth ability.

3. Characteristics of project productivity

According to the viewpoint of system theory, project productivity itself is a diversified system; and there are fundamental elements, expansibility elements and modularity elements in this system. Fundamental elements include means of labor concerning on means of production, subject of labor and the labors who work on production of material goods; expansibility elements are mainly science, technology and advanced construction technology; modularity elements include management organization and information communication. Its system possesses the organic integrity of quality, quantity and space-time structure.

Generally speaking, project productivity possesses four characteristics: First is effectiveness. The primary goal to run project productivity is to gain economic benefits. Benefit is the economic base to survive project organization and construction enterprise, and the effectiveness reflects the economic capability of project productivity. Second is innovation. The construction process of engineering project is featured by "one-piece customization", and each engineering project adopts different construction process and technical method according to its function standard, which requires to boost technical progress and management innovation constantly. The innovation is the soul of sustainable progress of project productivity, reflecting the driving force of project productivity level improvement. Third is intensiveness. The literal meaning of intensiveness refers to a kind of operating mode which is realized through the improvement of economic elements quality and elements configuration, the 
concentration of elements input and adjustment to compound mode of elements in social and economic activities, and in same economic range, leading to increase economic benefits and the maximum output return with rational cost input. Intensiveness reflects the market competitiveness of project productivity. Fourth is diversity. From the perspective of capital composition and technology structure of project productivity factors, project productivity appears various forms; from the perspective of whole function of project productivity, project productivity also appears with multilevel ability, such as, professional contract, engineering overall contract and project groups contract, etc., the corresponding management organization mode and relation also exists great difference.

4. Further research of project productivity theory

With industry development and the overall progress of construction industry, the three major elements of project productivity are further deepened, and the theoretical research of project productivity is also extended.

As the dominant factor of demand, labor force goes through fundamental changes. It mainly expresses three aspects: The first is that the administrative staff changes from a single position worker into a comprehensive labor who possesses the ability of one major for various positions, can be competent for general work; second, the front line workers start to be adapted to complicated process changes and handling requirements of consolidated skills; third, it is required that there is a batch of laborers who can master certain skill tool and intelligent equipment.

Labor means factors mainly take production tool and equipment as the key symbol of advanced productivity development level, which reflects the great advancement. The use of advanced tool and equipment reduces labor intensity, increases labor efficiency, improves working environment, and ensures production safety and occupational health for laborers, which fully reflects the management concept of people first.

The object of labor is also undergoing a qualitative leap. Building volume and height is gradually expanded, space and underground development is changed with each passing day, meanwhile,engineering scale in water conservancy, transportation and electricity is continuously expanded, all of which have posed a new challenge for construction industry. At the same time, the continuous improvement of structure, function and usage demand has thus made the object of labor abstract and complex day by day.

Either the change of laborer demands or the change of labor means and labor objects, they depend on the technological progress and management innovation in essence. According to the view that science and technology can be transformed into actual productivity in the first time, we can conclude that it is project productivity that acts in the successful practice of engineering project management, and the most core theoretical guidance is Marx's theory of productive forces. This lays a theoretical foundation for our exploration of research on the deepening of "project productivity".

Here, what is also necessary to be pointed out is that, for making research innovation and increasing development project productivity theory, it is required to attach great importance to the research of productive relations, since the productive relations of projects are mainly reflected in the position and mutual relationship between each implementation subject in project management as well as interest distribution and responsibility allocation. Project productivity and productive relations are intensively reflected into production mode, while the core of production mode lies in organization form, management style and operating procedure.
(3) The transformation of production mode in construction industry Combining the theory research of Chinese engineering project management with its practice, the transformation of production mode in construction industry primarily reflects in four aspects.

1. The transformation of workers

Changing from popular labor management mode in theearly planned economic times, into relative independent operation mode of labor level, the labor force is more intensive, professional and effective. We proposed the "two level departed" organizing-production mode in the early 1990s. The separation of management-level and laborlevel makes project management more outstand and smooth, reflecting a progress of construction business in productive forces.

With the development of construction business, the requirements to workers become higher and higher, transforming form professional type to high-tech, high-quality and synthesizing type. This require those workers to have several professional knowledge, production skills and position certificate, and relevant employment demands are proposed; this also emphasizes a mixed ability of workers, requires one-professional and multi-talented, especially those highend talents need to know technology, management, laws and regulations, to be good at operation, management, coordination, to be relative interdisciplinary talents; this emphasizes workers' high-quality, and requires them to increase the working-level and working-efficiency; workers need to have some educational qualities, higher occupational morality consciousness, love and respect their jobs, adapt to the age's development and what social culture requires to the masses.

2. The transformation of labor means

The construction industry always stayed at the application of traditional means of labor in a relatively long 
period, with the social progress and technological development, especially after implementing the modern project management and operation mode, the progress of productive forces are stimulated extremely, the means of labor has also changed, new means, new technology, new tools, new equipments emerge in an endless stream, changing rapidly. The requirements for means of labor is increasingly transferred to the development direction of high efficiency, high quality, and low consumption, especially along with the trend of three concepts of "science and technology, humanity, green" for Olympic project and the surge of ecological civilization construction industry, thus a large number means of labor with strong productivity, high work efficiency, low labor strength, energy conservation, emission reduction and environmental protection emerge. Labor means shall even reflect intellectualization, humanization and low carbonization.

3. The transformation of object of labor

The quality and level of construction products have changed tremendously during China's reform and development period of almost forty years, and the construction quality, architectural image, and building function even develop by leaps and bounds. Building products with monotonous style in the past are gradually replaced by social progress. Since 1990 s, we began to implement project and engineering management, which contributed to the qualitative leap of quality and function of construction products. People realized soberly, as for the progress of productivity in construction industry and the improvement of production mode, we should pay significant attention and guide construction products to transform into scientific and technologic type, low-carbon type, intelligent type and humanity type gradually, then improve building functions step by step. Enhance the architectural application of science and technology as well as technological products; strengthen the exploration, development and application work of patented technology, intellectual property and excellent know-how; improve the technology content of architectural design, building operations and building products; promote the ability which construction business enterprise has in every process of building products' total life circle and promote deeper reforms that construction business enterprise can adapt.

4. The transformation of productive relations

The overall progress of construction productivity determines the change of production relations. Meanwhile, with the development of national economy and the improvements of market economy, the change of production relations towards construction industry has made a great contribution.

(1) The transformation of status and relationship among all implementing subjects

The status and relationship among traditional construction units, investigation units, design units, supervise units, implementation units, supply units and labor units have changed obviously. Especially with the appearance of different market forms, such as the general contract, agent-construction system and project management companies, the status and relationship among all implementing subjects are becoming equal and mutually beneficial step by step. At the first stage of project management, due to the differences between status and relationship, the modification principles and methods of different levels are also different. With the research and deepening of productivity in construction industry, more attentions are paid to transforming the position and relation of each subject, forming a big team by centering on project construction, working in a team manner, communicating by using team principle, and making cohesion via team concept, so as to reflect the harmony and efficiency between each implementation subject at the largest extent.

\section{(2) The transformation of profit} relationship between and among all implementing subjects

It is very important to change the production mode of construction and the profit relationship. We should insist the cooperative principle of equality and mutual benefitand win-win situation, propose the cooperation and mutual benefits relationship of benefit integration, reform contracting mode and contract management mode, reflecting the highly integrative cooperation of responsibility, power and benefit. Change the concept of contract management, and achieve the management style of people-oriented, harmony and unity of objective. Change the narrowminded concept of pursuing the profit, reduce the contract disputes and keep a healthy contract relationship.

\section{(3) The transformation of} responsibilities and rights division of all implementing subjects

The allocation of responsibilities and rights is the feature work of project management. With the progress of architectural productivity, the traditional relation of responsibilities and rights is changed, which fully reflects the management concept of responsibility sharing, power co-fusion and interest sharing. Aiming at the construction project, the responsible persons of all parties should draw a clear distinction firstly, meanwhile, reflect the overall responsible thoughts, and really realize the division of labor responsibility but not divide up with each other, finally, they should be responsible for the project, the society and users with strong sense of responsibility. As for powers of all parties, power penetration and cross and fusion should be done within the project management, and the positive interaction 
shows the scientific and humanized characters of power. Subjects of all parties can cooperate with each other around the whole profit of the project, and deal with the profit relationship from the perspective of long-term cooperation.

\section{(4) "Project Productivity" theory has laid a solid foundation for the successful practice of profound revolution of construction production mode in our country}

With the support of "project productivity" theory, we have successfully achieved the deep transformation of construction production mode. For more than twenty years, when we have learned the four stages(scheme, design, construction and pilot run) of International project management, and five processes(launch, plan, implementing, control and conclusion), we use the viewpoint of "project productivity" theory to carry out deep and wide studies of the productive relations of Chinese construction industry, and by reforming the internal management systems of construction enterprises and transforming their operating systems, we can achieve practices like two-level independence, two-line separation, matrix-type organization and flat management, constantly adjust productive relations and push forward the optimal allocation and dynamic management of three major factors, namely laborer, means of production and objects of labor, which greatly emancipates and develops the productive forces of construction.

1. Establish the project management department to realize project manager responsibility system

The organizational form of the project productivity is the project management department, which is a new thing that appears in promoting Lubuge project management experience and enterprise reform and development of construction industry. Since the beginning of 1987 , the project manager department developed from nothing, grew quickly, and became perfect day by day, spread all over the country, and also gradually built and perfected the responsibility system of project manager and the project cost calculation system during the development process. Currently, the construction of "two systems" became the basic management system generally adopted by Chinese construction enterprises, which provided new operation pattern for the enterprises optimizing configuration of social production elements, developing project productivity and enlarging operating scales. The responsibility system of project manager possesses four features, including object uniformity, content comprehensiveness, subject substantialized and responsibility risk. Its implementation realized two negations and two effectivities fundamentally: Negating the administrative order commanding production, negating that conducting economic calculation according to administrative level is the effective way to solve the issue lacking responsible person for project, however, it motivates energy of project implementation, and promotes the effective system of economic benefits of project and the social benefits of enterprise. From the change process from project management contract system proposed in 1980 s in the early stage of China's reform on construction industry to project manager accountability system proposed in $1990 \mathrm{~s}$ then to project manager responsibility system later, it can be seen that, although it is different in words like contract, accountability and responsibility, it clearly shows that China has continuously deepened its reform and improved its operating system for the construction industry, and the track of promoting and implementing project management also finally forms the scientific positioning of "Three One-time" for today's engineering project management. In other words, the project serves as the core of disposable cost management, the department of project manager serves as the temporary organization institution of disposable construction and production, and the project manager serves as the disposable authorization manager for legal representative of the enterprise. The three "one-time" not only effectively eliminated the disadvantages of the project contract system in the past, and has played a powerful role in promoting change in the way of project production, but also truly reflected the basic principles of "project management organization levels decrease, highly efficient personnel allocation, management object is directly in place, project resource optimization combination, and dynamic management".

2. Establish a new enterprise operation mechanism which adapt to the construction project management

Through the implementation of project resource optimization combination, and dynamic management, we straighten out the relationship of the three levels of the enterprise, projects and assignments. Firstly, emphasize the enterprise level is the center of business, covering the main body legal liability category, and it includes three main bodies: The main body of the market competition, the performance, and the responsibility enterprise stakeholders. Secondly, clear the project-level is the implementation center of management, in charge of the realization of the management goals of quality of engineering projects, time limit for a project and cost, etc. Further clear the relationship between business-level and projectlevel is service and compliance, supervision and implementation, that is to say, the regulation system for enterprise level production elements needs to serve the optimization configuration of project level. The dynamic management of project levels' production elements shall submit to macro-control of enterprise levels. Project level and 
the level of labor service have mutually-equal contractual relation, the development direction of labor service level is professionalization, socialization and enterprise independence; the relationship between enterprise legal representative and the project manager is a mandate and authorization management, there is no centralized and decentralized problems between them, which forms a new type of construction project management operation mechanism of "headquarter service regulation, projects authorization management, professional implementation safeguard, social force cooperation".

3. Form the basic framework system of project management with "trinity" as principal line

In the past twenty years, construction enterprises and experts in our country took promoting "project productivity" as theoretical basis, guided project management practice, precisely organized the construction, which has created and accumulated many new successful experiences. In conclusion, it can be intensively and brightly reflected as the basic framework system for engineering and project management which takes "separation of bid price, process boutique and project culture" as the main line.

Main features: Dynamic management, optimized allocation, target control, node assessment;

Operation mechanism: headquarter service regulation, projects authorization management, professional implementation safeguard, social force cooperation;

(3) Organization structure: "Two layers separation, three layers relationship ", that is to implement the separation of management layer and operational level, process the relationships between project layer and enterprise layer, project management and enterprise legal representative, project management team and labor operation layer;

(4) Pushing subject: "Construction of two systems and three upgrades", that is: Comprehensively strengthen responsibility system of project manager and the construction of project cost accounting system; realize the upgrade of technology progress and innovation management, general contracting management and capital operation capacity, staff quality and intelligence structure of enterprises;

(5) Basic content: "Four controls, Three manages, One coordination", namely, well control of procedure, quality, cost, safety, reinforce construction site (element) management, information-oriented management, contract management and organizing communicating coordination ;

(6) Management objectives: "Four ones", that's to form one set of project management theory and method which not only has Chinese characteristics, but also tracks with international practice, adapts to market economy, is accessible and more systemic; train and build up a talent team of engineering project management that has certain professional knowledge, knows laws, can operate business, is good at management, responsible and with a hard attitude; develop and apply a generation of new materials, techniques, devices and technologies that can relatively rapidly promote the increase of productivity level and optimize the organic composition of enterprises; construct, summarize and popularize a batch of typical projects that have high quality, efficiency and speed, and fully show the level of technology and contemporary management strength with international level.

Review and summarize all practical explorations and theoretical researches conducted in the process of promoting engineering project management, and reflecting the current problems profoundly. Although we have already achieved remarkable progress, this achievement is just periodical, especially when there are significant gaps with the development demand of international project management. With the development of economic globalization, there is fierce competition in domestic and foreign markets, ups and downs of financial crises, deep-level reforms of economic system and constant adjustment of industrial structure. Facing various continuous challenges, China's construction industry shall constantly update its development concept to advance with the times, further expand new theoretical connotation, create new core value system, adapt to new development trend, comprehensively review research and further increase the innovation of "Project Productivity" theory, continuously deepen engineering project management, which possesses extremely important historical and practical significance to solve the external factors restricting the reform and development in current construction industry, and enterprise transformation and updating, etc., thus, preferably adapting to the sector demands of liberating and developing construction productivity under new trends.

\section{Conclusion}

Nowadays, China is facing a new historic opportunity of development, and fully implementing the $12^{\text {th }}$ five-year economic development plan, changing the way the building industry grows and helping companies move up the value chain requires continued reform, persistent focus on innovation of construction project management practice and greater effort to enhance the core competitiveness of building enterprises, with a view to changing building industry into a top-performing industry, a low-carbon industry, a socially responsible and well-respected, trusted industry and a modern industry with high level of technology content and managerial innovation. 


\section{References}

$\mathrm{Hu}$ Jintao, a report at the 18 th national congress of CPC "forging ahead towards socialism with Chinese characteristics and endeavoring to build a well-off Chinese society." People's Publishing House

Zhang Qinlin, Guide to Project-based Construction Practice, China Architecture \& Building Press, September 1997

Cheng Hu, Cong Peijing, Construction Project Management, China Architecture \& Building Press, June 2001

Wu Tao, Study and Application of Construction Project Management Practice, China Architecture \& Building Press, February 2004.

Zhang Qinlin, Project Management and Building Industry, China Architecture \& Building Press, August 2006

Continued Education and Training Textbook for Class A certified Builder in Construction Engineering, China Construction Industry Association, China Architecture \& Building Press, September 2011.

Project Management Committee of China Construction Industry Association, China Construction Project Management Knowledge System (2nd edition), China Architecture \& Building Press, January 2011. 